\title{
PENGARUH STRES DAN KOMUNIKASI TERHADAP PRODUKTIVITAS KEPALA SEKOLAH DASAR NEGERI DI KECAMATAN KOJA JAKARTA UTARA
}

\author{
Christie G. Mewengkang*
}

\begin{abstract}
The objective of this research is to obtain information about the effect of stress and communication on productivity of the principal's of elementary school. The research was conducted to all of state the principles of elementary school in the district of Koja, the city of North Jakarta by using of survey method with path analysis applied in testing hypothesis. The research concludes: (1). There is direct effect of stress on productivity. (2). There is direct effect of communication on productivity. (3). There is direct effect of stress on communication. Therefore to enhance the principles of elementary schools productivity can be carried out by stress and communication.
\end{abstract}

Keywords: Stress, communication, productivity.

\section{PENDAHULUAN}

Kepala sekolah sebagai salah satu sumber daya dalam mengelola pendidikan di sekolah, harus memiliki kemampuan dan kecakapan dalam menyelenggarakan kegiatan pendidikan dengan baik. Kepala sekolah harus mampu melaksanakan tanggung jawab yang diembannya serta mampu melakukan keterampilan-keterampilan konseptual, manusiawi dan teknis, serta dapat memotivasi para bawahan yang dipimpinnya. Dengan demikian yang dimaksud dengan kepala sekolah yang produktiv bukan hanya sekedar suatu jabatan, tetapi juga menuntut keahlian dalam melaksanakan tugastugasnya secara efisien dan efektif.

Kepala sekolah juga harus profesional, dalam artian bahwa ia mampu merumuskan mutu lulusan yang ideal untuk satuan pendidikan yang dipimpinnya. Untuk itu, setiap kepala sekolah harus mampu mendeskripsikan indikator dan kriteria mutu lulusan yang dicita-citakannya sebagai landasan pengembangan visi, misi, dan tujuan dari organisasi yang dipimpinnya, dan untuk mewujudkan hal tersebut tentunya harus didukung oleh perencanaan dan strategi yang baik pula.

Dalam organisasi sekolah, kepala sekolah merupakan salah satu komponen pendidikan yang memiliki peran dalam mengelola penyelenggaran kegiatan pendidikan dan pembelajaran di sekolah. Seorang kepala sekolah memiliki tugas pokok yaitu menggali dan mendayagunakan seluruh sumber daya yang ada di sekolah secara terpadu untuk dalam mencapai tujuan pendidikan/sekolah secara efisien dan efektif. Hal tersebut seperti yang dimaksudkan dalam Permendiknas No. 13 Tahun 2007 tentang standar kompetensi kepala sekolah.

Sebagai seorang individu, kepala sekolah dihadapkan pada berbagai tekanan, baik yang datang dari beban kerjanya, lingkungan, maupun yang berasal dari dalam diri pribadi kepala sekolah itu sendiri. Tekanan ini bisa menjadi faktor pemicu timbulnya stres terhadap diri pribadi seorang kepala sekolah, yang secara langsung dapat mempengaruhi dalam melaksanakan tugas dan fungsinya sebagai pemimpin pendidikan di sekolah.

\footnotetext{
* Dosen STAKN Manado
} 
Beberapa kondisi tersebut tentunya memberikan pengaruh terhadap kemampuan kepala sekolah, baik dalam kinerjanya maupun berinteraksi dengan guru, pegawai, siswa maupun orang tua dan masyarakat. Tidak terjalinnya interaksi yang harmonis antara kepala sekolah dengan guru, siswa dan masyarakat akan menghambat tugas kepala sekolah sebagai tokoh sentral yang mempunyai peran yang sangat strategis dalam tercapainya penyelenggaraan pendidikan yang bermutu.

Seorang kepala sekolah dituntut keahliannya dalam memimpin dan mengembangkan struktur organisasi dengan efisien sehingga sumber daya yang tersedia dapat dimanfaatkan dengan semaksimal mungkin demi tercapainya tujuan yang sudah ditetapkan. Oleh karenanya, produktivitas kepala sekolah menjadi hal yang sangat penting untuk diperhatikan.

Dengan latar belakang tersebut, maka peneliti tertarik untuk melakukan penelitian lebih dalam tentang produktivitas kepala sekolah. Serta mencoba mengungkapkan apakah stres dan komunikasi dapat mempengaruhi kepala sekolah untuk menjadi pribadi yang produktif, yang tercermin dari pelaksanaan tugasnya dengan efektif dan efisien.

\section{Produktivitas}

Produktivitas tidak hanya membicarakan ilmu yang terdapat dalam kajian ilmu manajemen, melainkan juga mengandung arti yang sangat dalam dan berorientasi pada sikap yang didasarkan pada kemauan yang kuat dan secara kontinyu berusaha mengarah pada proses pencapaian suatu tujuan yang baik dan diinginkan. Produktivitas secara individu menggambarkan potensi, persepsi dan kreatifitas seseorang yang senantiasa ingin menyumbangkan kemampuannya agar bermanfaat bagi diri dan lingkungannya. Hal ini menggambarkan potensi pribadi seseorang, bahwa individu yang dikatakan produktif adalah orang yang dapat memberikan kontribusi nyata dan berarti bagi lingkungannya, imaginatif dan inovatif dalam memahami persoalan hidupnya serta kreatif dalam mencapai tujuan hidupnya.

Robbins dan Judge (2011:58) mendefinisikan produktivitas sebagai, "an organization is productive if it achieves its goals by transforming inputs into outputs at the lowest cost. Thus productivity requires both effectiveness and efficiency. Sebuah organisasi dikatakan produktif, jika dalam pencapaian tujuan organisasinya dapat mengubah input menjadi output dengan biaya terendah, dengan kata lain produktivitas membutuhkan efektifitas dan efisiensi.

Konsep yang sama tentang produktivitas seperti yang dikemukakan Griffin (2002:668) bahwa produktivitas dalam pengertian umum merupakan ukuran efisiensi ekonomis yang merangkum biaya yang relatif dari output dibandingkan dengan nilai input yang diperlukan untuk menghasilkan output tersebut. "In a general sense, productivity is an economic measure of efficiency that summarizes the value of outputs relative to the value of the inputs used to create them". Produktivitas selanjutnya didefinisikan Wood, et.al, (1998:19) juga merupakan suatu rangkuman pengukuran dari kuantitas dan kualitas kinerja yang dicapai, serta juga memerlukan adanya perhitungan pemanfaatan sumber daya. "Productivity is a summary measure of the quantity and quality of work performance achieved, which also takes resource utilisation into account".

Lebih lanjut Schermerhorn (2010:12) mengemukakan bahwa, "productivity involves two common performance measures effectiveness and efficiency". Produktivitas merupakan dua ukuran umum kinerja yaitu efektivitas dan efisiensi. Konsep lain tentang produktivitas menurut Mahoney sebagaimana yang dikutip oleh Bartol et al, (2003:539) 
"producitivity is an efficiency concept relating the ratio of otuputs to inputs in a productive process". Produktivitas merupakan konsep tentang efisiensi yang berhubungan dengan rasio output dengan input di dalam suatu proses produksi. Lebih lanjut Bartol et al, mengemukakan tentang produktivitas merupakan penilaian efisiensi kinerja organisasi yang dilihat dari rasio output terhadap input.

Berdasarkan beberapa uraian konsep di atas dapat disintesiskan produktivitas adalah kuantitas dan kualitas kerja yang dihasilkan oleh seseorang dengan memanfaatkan sumber daya yang ada dengan efektif dan efisien dengan indikator: jumlah target yang dicapai, kecepatan menyelesaikan pekerjaan, mutu hasil pekerjaan, dan efisiensi pemanfaatan sumber daya.

\section{Stres}

Stres secara umum didefinisikan sebagai keadaan atau kejadian yang di alami seseorang yang membuat dirinya merasa tidak nyaman dan bahkan merasa tertekan. Stres juga sering diartikan sebagai suatu pengalaman subyektif seseorang yang diakibatkan oleh adanya kesenjangan antara kenyataan yang terjadi tidak sesuai dengan harapannya. Secara teknis psikologis stres dartikan sebagai proses penyesuaian seseorang terhadap situasi yang dipersepsinya menantang atau mengancam kesejahteraan orang bersangkutan.

Definisi serupa juga disampaikan oleh Hughes, Ginnet, dan Curphy (2009:341) "stress as the process by which we perceive and respond to situations that challenge or threaten us". Kondisi ini menyebabkan timbulnya perasaan marah, cemas dan frustrasi. Secara teknis psikologis stres dartikan sebagai proses penyesuaian seseorang terhadap situasi yang dipersepsinya menantang atau mengancam kesejahteraan orang bersangkutan.

Definisi serupa juga disampaikan oleh Hughes, Ginnet, dan Curphy (2009:341) "stress as the process by which we perceive and respond to situations that challenge or threaten us". Stres merupakan sebuah proses di mana dan bagaimana kita menanggapi situasi yang menantang atau mengancam kita. Sehingga tanggapan terhadap stres ini pada setiap individu memiliki pengaruh yang negatif.

Robert Kreitner dan Angelo Kinicki (2009:599) mendefinisikan stres sebagai, "an adaptive response, mediated by individual characteristics and/or psychological processes, that is a consequence of any external action, situation, or event that places special physical and/or psychological demands upon a person". Stres merupakan sebuah respon adaptif dari setiap individu yang dipengaruhi oleh karakter dari setiap pribadi atau proses psikologi yang merupakan kosekuensi dari setiap tindakan atau situasi, keadaan dari luar sehingga menyebabkan adanya tuntutan psikologis maupun fisik yang khusus pada seseorang.

Pendapat lain tentang stres seperti dikemukakan oleh Colquitt, LePine dan Wesson (2011:144) "stress is defined as a psychological response to demands that possess certain stakes and that tax or exceed a person's or resources". Definisi ini memberikan pengertian bahwa stres sebagai respon psikologis terhadap suatu tuntutan tertentu serta memiliki beban yang melampaui kemampuan seseorang atau sumber daya tersebut. Daft (2010:460) dalam bukunya "New Era of Management" mendefinisikan stres sebagai berikut: "Stress is an individual's physiological and emotional response to external stimuli that place physical or psychological demands on the individual and create uncertainty and lack of personal control when important outcomes are at stake". Stres adalah suatu reaksi fisik maupun emosional terhadap rangsangan atau stimulus yang timbul dari luar dirinya baik itu secara fisilogis maupun psikologis seseorang. 
Stres secara alami diartikan sebagai suatu rangsangan, perasaan gelisah dan tekanan secara fisik yang terjadi pada seseorang dimana hal tersebut menimbulkan suatu tekanan pada orang tersebut yang melampaui kemampuan individu tersebut untuk mengatasinya, seperti yang dikemukakan Slocum, Hellriegel (2011:221) "stress is the excitement, feeling of anxiety, and/or physical tension that occurs when the demands placed on an individual are thought to exceed the person's ability to cope". Kepala sekolah sebagai seorang individu juga tidak lepas dari permasalahannya. Sebagai seorang pemimpin sebuah organisasi sekolah, banyak hal dan permasalahan yang mungkin dapat menyebabkan stres, sehingga dapat memempengaruhi produktvitasnya dalam menjalankan tugas dan tanggung jawabnya sebagai kepala sekolah.

Dari beberapa pendapat atau konsep yang dikemukakan tentang stres, maka dapat disintesiskan stress adalah kondisi seseorang sebagai tanggapan terhadap tekanan baik dari dalam diri maupun lingkungannya dengan indikator gangguan psikologis, gangguan fisiologis serta gangguan berperilaku. 


\section{Komunikasi}

Komunikasi merupakan salah satu unsur yang penting dalam sebuah proses sosialisasi. Manusia sebagai mahluk sosial tidak akan bisa lepas dari komunikasi, karena dengan komunikasi setiap orang atau individu dapat menyampaikan dan saling bertukar informasi tentang maksud serta tujuannya satu dengan yang lain. Dalam pengertian sederhana komunikasi dapat diartikan sebagai penyampaian dan pemahaman makna, baik dalam bentuk perkataan maupun tulisan diantara individu yang satu dengan yang lain.

Hal tersebut seperti yang dikemukakan oleh Robbins dan Coulter (2012:432-433) bahwa: Communication is the transfer and understanding of meaning. Note the emphasison the transfer of meaning: If information or ideas have not been conveyed, communication hasn't taken place. The speaker who isn't heard or the writer whose materials aren't read hasn't communicated. Pendefinisian lain komunikasi komunikasi adalah proses pertukaran informasi dari satu orang dengan orang yang lain. Hal ini dikemukakan oleh Griffin (2002:557) bahwa, "communication is the process of transmitting information from one person to another". Komunikasi dimaknai juga sebagai penyampaian informasi dan pemahaman dari satu orang ke orang lain. Komunikasi merupakan sebuah cara untuk menyampaikan ide-ide, fakta-fakta, pendapat, perasaan, dan nilai-nilai tertentu pada orang lain dengan tujuan agar penerima pesan memahami pesan sebagaimana yang dimaksud pengirim pesan.

Seperti yang dikemukakan Newstrom dan Davis (2002:47): Communication is the transfer of information and understanding from one person to another person. It is a way of reaching others by transmitting ideas, facts, thoughts, feelings, and values. Its goals is to have the receiver understand the message as it was intended. Robert P. Vecchio (2006:256) komunikasi dapat juga didefinisikan sebagai, "exchange of messages between persons for the purpose of constructing common meanings. Komunikasi merupakan pertukaran pesan di antara orang-orang dengan tujuan membentuk sebuah makna atau pengertian yang sama diatara satu dengan yang lain.

Pada kenyataannya, menurut Richard L. Hughes (2009:341) efektivitas proses komunikasi bergantung pada keberhasilan terintegrasinya semua langkah dalam suatu proses komunikasi. "In reality, the effectiveness of the communication process depends on the successful integration of all of the steps in the communication process." Dari definisi tersebut, komunikasi pada dasarnya tidak hanya berbicara tentang penyampaian pesan dari pemberi ke penerima pesan tersebut, tetapi sesungguhnya memiliki beberapa fungsi lain.

Sebagaimana yang dikemukakan Scott dan Mitchel, seperti yang dikutip oleh Robbins dan Coulture (2012:433) bahwa, "communication serves four major functions: control, motivation, emotional expression, and information". Komunikasi memiliki empat fungsi utama yaitu, pengawasan, fungsi motivasi, mengekspresikan perasaan atau emosi, dan pemberian informasi. Sehingga komunikasi memiliki peran yang penting dalam menerapkan fungsi-fungsi manajemen dalam sebuah organisasi. Hal ini secara langsung membuat seorang manajer harus memiliki kemampuan dan keahlian yang baik dalam berkomunikasi.

Komunikasi bagi seorang kepala sekolah dapat berfungsi dalam dia melakukan pengawasan terhadap para siswa maupun guru serta memberikan motivasi, mengekpresikan emosi atau perasaannya, dan memberikan informasi tentang berbagai hal di sekolahnya baik kepada para guru, siswa, orang tua bahkan kepada masyarakat di lingkungan sekitar sekolah. Dengan memperhatikan serta melaksanakan fungsifungsi tersebut diharapkan kepala sekolah dapat melaksanakan segala tugas dan 
fungsinya sesuai dengan wewenang yang ada padanya secara efektif dan efisien demi tercapainya tujuan yang diharapkan.

Dari berbagai konsep para ahli di atas, maka dapat disintesiskan komunikasi adalah penyampaian informasi antara individu atau dari orang yang satu ke seorang atau kelompok lain dengan tujuan agar tercapai pemahaman makna yang sama antara mereka dalam upaya memecahkan permasalahan yang ditemui untuk mencapai tujuan yang diharapkan, dengan indikator: penyampaian informasi/pesan, penerimaan pesan, dan umpan balik pesan.

\section{METODE}

Tempat dan objek dalam penelitian ini adalah seluruh Sekolah Dasar Negeri di Kecamatan Koja Jakarta Utara, dengan populasi seluruh Kepala Sekolah Dasar Negeri di Kecamatan Koja Jakarta Utara yang berjumlah 72 orang dengan cara penentuan sample yang digunakan adalah simple random sampling yang menghasilkan 61 orang responden. Metode yang digunakan dalam penelitian ini adalah metode survei dengan menggunakan kuesioner sebagai alat pengukur.

Penelitian ini menggunakan analisis jalur (Path Analysis) untuk mengetahui adanya pengaruh antar variabel sesuai dengan modelkausal yang terbentuk. Sebelum kuesioner digunakan dalam penelitian ini terlebih dahulu dilakukan ujicoba untuk menentukan validitas dan reliabilitas instrumen. Hasil tersebut digunakan sebagai instrumen untuk mengambil data penelitian dilapangan. Analisis data meliputi: 1) deskripsi data, 2) uji prasyarat analisis normalitas, 3) analisis jalur yang meliputi: analisis model, pengujian hipotesis dan penentuan tingkat pengaruh.

\section{HASIL DAN PEMBAHASAN}

\section{Pengaruh langsung negatif Stres $\left(X_{1}\right)$ terhadap Produktivitas $\left(X_{3}\right)$}

Dari hasil perhitungan diperoleh nilai koefisien jalur Pengaruh langsung Stres terhadap Produktivitas Kepala Sekolah Dasar Negeri di Kecamatan Koja Jakarta Utara. Dari hasil perhitungan diperoleh nilai koefisien jalur $p_{31}=-0,325$ dan nilai koefisien korelasi $r_{13}=-0,445$. Hasil penelitian ini seperti yang dikemukakan oleh Robbins dan Judge: As you might imagine, stressful daily events at work (a nasty e-mail, an impending deadline, the loss of big sale, a reprimand from the boss) negatively affect moods. The effects of stress also build over time. As the authors of one study note, "a constant diet of even low-level stressful events has the potential to cause workers to experience gradually increasing levels of strain over time.

Kreiner dan Kinicki juga mengungkapkan adanya hubungan negatif antara stres kerja dan kepuasan kerja, komitmen organisasi, semangat kerja, kinerja, dan turnover (pergantian) tenaga kerja atau karyawan. "Workplace stress is negatively related to job satisfacion, organizational commitment, positive emotions, performance, and turnover".

Greenberg dan Baron juga mengungkapkan bahwa saat ini jelas kelihatan stres memberikan pengaruh negatif terhadap kinerja tugas para pekerja. "The most current evidence available suggests that stress exerts mainly negative effects on task performance".Dengan demikian hipotesis 1 yang menduga terdapat pengaruh langsung negatif stres terhadap produktivitas dapat diterima. Hal ini mencerminkan bahwa semakin meningkatnya stres yang dialami kepala sekolah akan mengakibatkan menurunnya produktivitas. 


\section{Pengaruh langsung positif Komunikasi $\left(X_{2}\right)$ terhadap Produktivitas $\left(X_{3}\right)$}

Dari hasil perhitungan diperoleh nilai koefisien jalur Pengaruh langsung positif Komunikasi terhadap Produktivitas Kepala Sekolah Dasar Negeri di Kecamatan Koja Jakarta Utara. Dari hasil perhitungan diperoleh nilai koefisien jalur $p_{32}=0,271$ dan nilai koefisien korelasi $r_{23}=0,415$.

Hasil penelitian ini sesuai dengan konsep yang dikemukakan oleh Lussier: Essentially, nothing can't get done in an organization without effective communications. Effectve communication strategies have increased productivity, improved efficiency, cut costs, improved morale, and decreased turnover: Lussier menjelaskan bahwa pada dasarnya organisasi tidak akan dapat mencapai tujuannya tanpa adanya komunikasi yang efektif di dalamnya. Dengan menggunakan strategi komunikasi yang efektif, dapat meningkatkan produktivitas, tercapainya efiiensi, penghematan biaya, adanya peningkatan moral yang baik, dan menurunkan absensi pekerja. Konsep teori yang lain tentang komunikasi dengan produktivitas seperti yang diungkapkan oleh Robbins dan Judge:

Perfect communication is unattainable. Yet a positive relationship exists between effective communication (which includes perceived trust, perceived accuracy, desire for interaction, topmanagement receptiveness, and upward information requirements) and worker productivity. Komunikasi sempurna dapat dicapai jika adanya hubungan yang positif antara komunikasi efektif (yang termasuk kepercayaan, adanya ketepatan, hasrat dan keinginan berinteraksi, keterbukaan dari manjemen puncak, dan adanya kebutuhan akan informasi dari atas) dan produktivitas pekerja. Hasil analisis hipotesis kedua menghasilkan temuan bahwa komunikasi berpengaruh secara langsung positif terhadap produktivitas. Berdasarkan hasil temuan tersebut dapat disimpulkan bahwa produktivitas dipengaruhi secara langsung positif oleh komunikasi. Meningkatnya komunikasi akan mengakibatkan peningkatan produktivitas.

\section{Pengaruh langsung negatif Stres $\left(X_{1}\right)$ terhadap Komunikasi $\left(X_{2}\right)$}

Dari hasil perhitungan diperoleh nilai koefisien jalur. Pengaruh langsung negatif Stres terhadap Komunikasi diperoleh koefisien jalur $p_{21}=-0.444$ dan nilai koefisien korelasi $r_{12}=-0,444$. Sehingga hasil penelitian ini sesuai yang dikemukakan Slocum dan Hellriegel: The potential effects of high levels of work stress occur in three main areas: physiological, emotional, and behavioral. Examples of the effects of serve distress in these areas are as follows: ... Behavioral effects of stress may include poor perfromance, absenteeism, high accident rates, high turnover rates, alcohol and substance abuse, impulsive behavior, and difficulties in communication. Salah satu dampak negatif stres adalah dampaknya terhadap perilaku dan kebiasaan seseorang, dari awalnya baik menjadi kurang atau bahkan tidak baik. Salah satu contoh yaitu sulit berkomunikasi dengan orang lain.

Hal yang senada dengan itu dikemukakan pula oleh Kreitner dan Kinicki bahwa, stres khususnya di tempat kerja memberi pengaruh negatif terhadap kepuasan kerja, komitmen organisasi, emosi yang positif/semangat, serta kinerja. Workpace stress is negatively related to job satisfaction, organizational commitment, positive emotions, performance, and turnover. Richard L. Hughes et.al, mengemukakan bahwa:As we have noted, too much stress can take a tool on individuals and their organizations. For individuals, the toll can be in terms of their healt, mental, and emotional wellbeing, job performance, or interpersonal relationship. 
Seperti yang diketahui bahwa stres berlebihan akan mendatangkan pengaruh yang tidak baik pada seseorang maupun organisasi. Pada seseorang akan memberikan dampak pada kesehatan, mentalnya, dan emosional, serta hubungan dengan orang lain seperti berinteraksi dan berkomunikasi. Sehingga dari teori di atas, ada dugaan stres berpengaruh terhadap seseorang dalam berkomunikasi dengan orang lain. Hasil hipotesis ketiga memberikan temuan bahwa stres berpengaruh langsung negatif terhadap komunikasi. Meningkatnya stres akan mengakibatkan menurunnya komunikasi.

\section{PENUTUP}

\section{Kesimpulan}

Berdasarkan hasil data penelitian dan hasil analisis data penelitian yang telah dibahas pada bab IV, dengan semua persyaratan analisis data yang meliputi uji linieritas serta keberartian regresi telah dipenuhi, maka dapat diambil beberapa kesimpulan sebagai berikut:

1. Terdapat pengaruh langsung negatif stres terhadap produktivitas. Artinya stres semakin meningkat, maka produktivitas akan menurun,

2. Terdapat pengaruh langsung positif komunikasi terhadap produktivitas, artinya jika komunikasi makin baik, maka produktivitas akan meningkat.

3. Terdapat pengaruh langsung negatif stres terhadap komunikasi. Hal ini menunjukkan bahwa semakin meningkatnya stres, komunikasi semakin kurang efektif.

\section{Saran}

Berdasarkan kesimpulan dan implikasi penelitian diatas dapat dikemukakan beberapa saran bagi peningkatan produktivitas Kepala SD Negeri di kecamatan Koja Jakarta Utara, sebagai berikut:

1. Faktor stres yang terjadi dan dialami kepala sekolahyang terkait dengan produktivitas hendaknya menjadi perhatian bagi kepala sekolah itu sendiri maupun pengawas. Sehingga dengan adanya perhatian, maka kepala sekolah diharapkan dapat memilki pengetahuan serta kemampuan untuk mengelola stres yang dialaminya.

2. Faktor komunikasi bagi kepala sekolah SD Negeri di Kecamatan Koja harus diperhatikan karena dengan adanya pengelolaan serta cara mengatasi stres yang baik, maka akan terjalin suatu komunkasi yang efektif antara kepala sekolah dengan pengawas, guru, para siswa, orang tua maupun masyarakat.

3. Untuk meningkatkan produkivitas: maka setiap kepala sekolah disarankan untuk lebih meningkatkan kemampuan dalam mengelola dan mengatasi stres, sehingga tidak menghambat dalam melaksanakan tugas dan tanggung jawabnya. 


\section{DAFTAR RUJUKAN}

Bartol, Kathryn. et al., Management: A Pacific Rim Focus, Enhance Edition. New South Wales: McGraw Hill, 2003.

Colquitt, Jason A. Jeffery A. LePine, dan Michael J. Wesson, Organizational Behavior: Improving Performance and Commitment in the Workplace. Second Edition New York: McGraw-Hill, 2011.

Daft, Richard L. New Era of Management Ninth Edition. USA: South-Western, Cengage Learning, 2010.

Frankel, Ack. R. and Norman E. Research in Education. New York: McGraw-Hill, 1989.

Griffin, Ricky W. Management Seventh Edition, New York: Houghton Mifflin Company, 2002.

http://ir-library.ku.ac.ke/ir/handle/123456789/6209?show=full diakses 25 Januari 2013.

http://laico.org/v2020resource/files/stress_jul-sep02.pdf diakses pada 26 Januari 2013.

Hughes, Richard L. Robert C. Ginnett, dan Gordon J. Curphy, Leadership: Enhancing the Lessons of Experience. Sixth Editon New York: McGraw-Hill, 2009.

Ivancevich, Konopaske and Matteson, Organizational Behavior and Management Eight Edition New York: McGraw Hill, 2008.

Ivancevich, John M. Robert Kenopaske, Human Resource Management. Twelfth Edition Singapore: McGraw-Hill International, 2013.

Kreitner Robert, Angelo Kinicki, Organizational Behavior. Seventh Edition. New York: McGraw-Hill, 2009.

Lussier, Robert N. Human Relations in Organizations: Application and Skills Building. New York: McGraw-Hill, 2008. 